\title{
РЕАКЦИОННАЯ СПОСОБНОСТЬ НЕКОТОРЫХ ПОЛИЦИКЛИЧЕСКИХ АРОМАТИЧЕСКИХ УГЛЕВОДОРОДОВ С ОН-РАДИКАЛОМ
}

V. TSEKULAJEV, I. SEVTSL'K. MONINGATE POLOTSOKLILISTE AROMAATSETE SUSIVESINIKE VOIME REAGEERIDA OH·RADIKAALIGA

V. TCHEKULAYEV, I. SHEVCHUK. REACTIVITY OF SOME POLYCYCLIC AROMATIC HYDROCARBONS WITH OH*RADICAL

\section{(Представил М. Губергриц)}

Окислительное превращение полициклических ароматических углеводородов (ПАУ) под воздействием такого агента, как гидроксильный

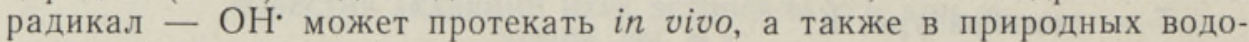
емах, обуславливая их самоочищение. Однако до настоящего времени отсутствуют данные о реакционной способности многих ПАУ, в том числе и канцерогенного бенз(а)пирена (БП), с указанным окислителем.

\section{Методика эксперимента}

Для определения относительных констант скоростей взаимодействия ОН-радикала с ПАУ использовался метод конкурентного акцептора. В роли последнего выступал синтезированный нами по методике ['] $n$-нитрозодиметиланилин (n-НДМА), предложенный в качестве специфичного акцептора для ОН·-радикалов [2]. Изучались следующие ПАУ: антрацен, пирен (оба х. ч.) и бенз (а)пирен (чистый) фирмы «Fluka AG» (Швейцария). Методика кинетического эксперимента заключалась в соокислении исследуемого ПАУ с $n$-НДМА при фотохимическом разложении водного раствора перекиси водорода, что, как известно [3], сопровождается генерированием ОН·-радикалов. 0,02 $M$ раствор перекиси водорода (х. ч.) облучался светом (с длиной волны 254 нм), выделенным с помощью интерференционного светофильтра из общего спектра излучения лампы ДРШ-1000.

Водные растворы изучаемых ПАУ приготовлялись следующим образом. В дистиллированную воду при перемешивании вводился раствор изучаемого ПАУ в ацетоне с последующим удалением ацетона вакуумной отгонкой. Следует отметить, что растворы ПАУ приготовлялись из расчета их растворимости в воде. Все опыты проведены при комнатной температуре $\left(22-25^{\circ} \mathrm{C}\right)$ и при $\mathrm{pH} 9$ (0,05 $M$ раствор буры). Определение содержания БП в водном растворе проводили с помощью метода Шпольского на спектрометре ДФС-12 при $77 \mathrm{~K}$. Исходные 


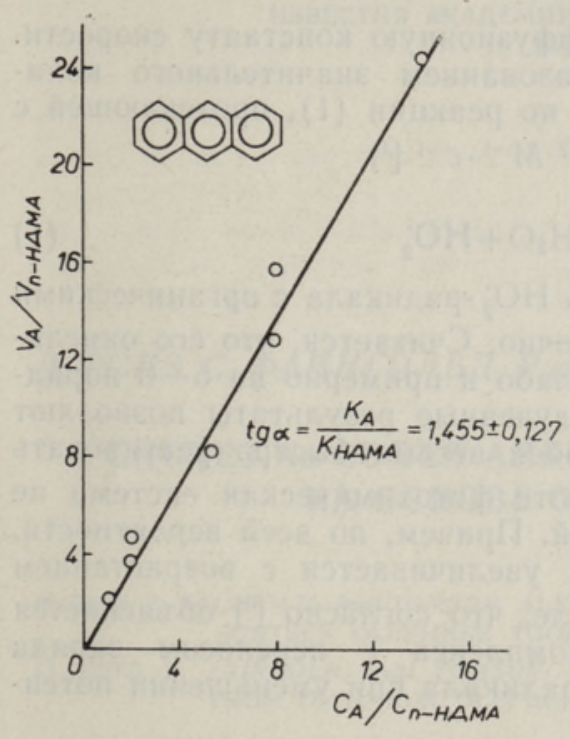

Рис. 1. Зависимость соотношения скоростей деградации антрацена и $n$-НДМА от соотношения их концентраций. $\left(\mathrm{C}_{\text {ант рацен }}=1 \cdot 10^{-6} \mathrm{M}\right)$.

Рис. 3. Зависимость соотношения скоростей деградации бенз(а)пирена и $n$-НДМА от соотношения их концентраций. $\left(\mathrm{C}_{\mathrm{БП}}=4 \cdot 10^{-10} \mathrm{M}\right)$.

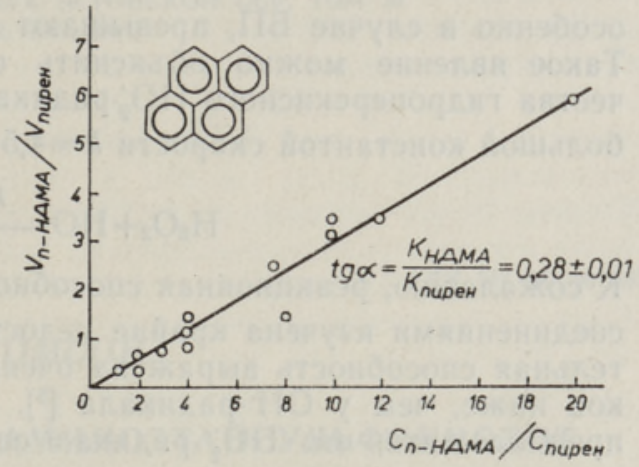

Рис. 2. Зависимость соотношения скоростей деградации пирена и $n$-НДМА от соотношения их концентраций. $\left(\mathrm{C}_{\text {пирен }}=5 \cdot 10^{-7} \mathrm{M}\right)$.

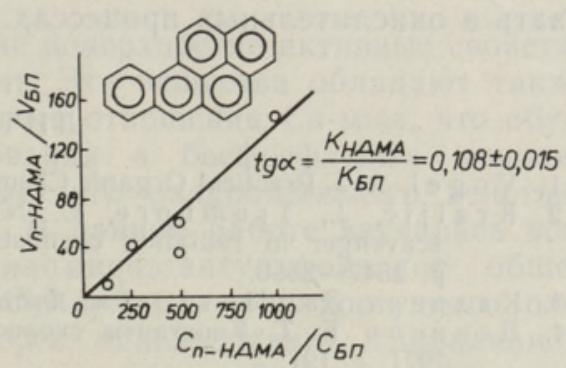

концентрации $n$-НДМА, пирена, антрацена, а также их изменения в ходе кинетического эксперимента определялись прямым спектрофотометрированием на приборе Specord UV VIS.

\section{Результаты}

Тангенсы угла наклона прямых (рис. 1-3) представляют собой соотношение констант скоростей взаимодействия гидроксильных радикалов с соответствующим ПАУ и $n$-НДМА. На основе полученных отношений расчитаны константы скоростей взаимодействия исследуемых ПАУ с ОН·-радикалом, поскольку для $n$-НДМА аналогичная константа составляет $7,5 \cdot 10^{9} M^{-1} \cdot c^{-1}\left[{ }^{4}\right]$. Таким образом, константа скорости взаимодействия $\mathrm{OH}^{*}$-радикала составляет для:

$$
\begin{gathered}
\text { антрацена }-(1,09 \pm 0,09) \cdot 10^{10} M^{-1} \cdot c^{-1} \\
\text { пирена }-(2,67 \pm 0,09) \cdot 10^{10} M^{-1} \cdot c^{-1} \\
\text { бенз (а) пирена }-(6,9 \pm 1,0) \cdot 10^{10} M^{-1} \cdot c^{-1}
\end{gathered}
$$

Как видно из приведенных выше результатов, полученные константы, 
особенно в случае БП, превышают диффузионную константу скорости. Такое явление можно объяснить образованием значительного количества гидроперекисного $\mathrm{HO}_{2}^{-}$-радикала по реакции (1), протекающей с большой константой скорости $k=4,5 \cdot 10^{7} M^{-1} \cdot c^{-1}\left[{ }^{4}\right]$.

$$
\mathrm{H}_{2} \mathrm{O}_{2}+\mathrm{HO} \stackrel{k}{\longrightarrow} \mathrm{H}_{2} \mathrm{O}+\mathrm{HO}_{2}
$$

$\mathrm{K}$ сожалению, реакционная способность $\mathrm{HO}_{2}$-радикала с органическими соединениями изучена крайне недостаточно. Считается, что его окислительная способность выражена очень слабо и примерно на 5-6 порядков ниже, чем у ОН-радикала [5]. Полученные результаты позволяют предположить, что $\mathrm{HO}_{2}^{;}$-радикал способен весьма быстро реагировать с ПАУ, поскольку примененная в работе фотохимическая система не содержит других частиц - окислителей. Причем, по всей вероятности, реакционная способность ПАУ с $\mathrm{HO}_{2}^{*}$ увеличивается с возрастанием числа ароматических циклов в молекуле, что согласно [6] объясняется увеличением энергии стабилизации комплекса с переносом заряда между молекулой ПАУ и перекисного радикала при уменьшении потенциала ионизации ПАУ.

Таким образом, реакция ОН-радикала с изученными ПАУ происходит с высокими значениями констант скоростей, что следует учитывать в окислительных процессах.

\section{ЛИТЕРАТ У РА}

1. V o g e 1, A. J. Practical Organic Chemistry. London, 1956, p. 573.

2. Kraljič,, J., Trumbore, C. N. p-nitrosodimethylaniline as an $\mathrm{OH}$ radical scavenger in radiation chemistry. - J. Am. Chem. Soc., 1965, v. 87, N 12, p. $2547-2550$.

3. К а л в е р т Дж., Пи т т с Дж. Фотохимия. М., 1968, с. 162.

4. Д ени и о в Е. Т. Қонстанты скорости гомолитических жидкофазных реакций. М., 1971 , c. 191.

5. В ы с оцк а я Н. А. Реакционная способность радикалов $\mathrm{OH}^{\circ}, \mathrm{O}^{-}, \mathrm{HO}_{2}$ и атомов кислорода в водных растворах ароматических соединений. - Успехи хим., 1973 , т. 42 , вып. 10 , с. $1843-1853$.

6. Полуэктов В. А. К механизму торможения органических веществ полициклическими ароматическими углеводородами. - Доклады АН СССР, 1970, т. 194, № 4 , c. $857-860$. 